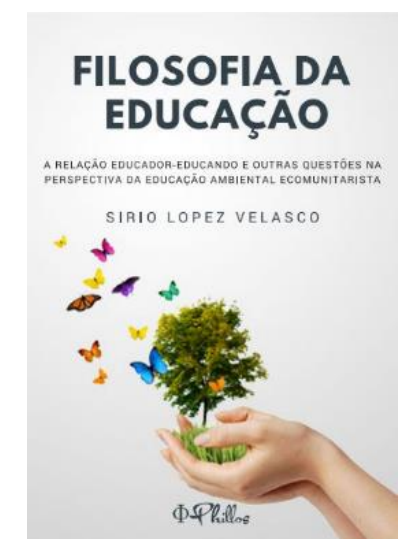

RESENHA: LOPEZ VELASCO, Sirio. Filosofia da educação: a relação educadoreducando e outras questões na perspectiva da educação ambiental ecomunitarista. Goiânia: PHILLOS, 2018, 122p [ISBN: 978-85-52962-00-7].

\title{
Filosofia da Educação
}

FÁBIO BATISTA ${ }^{1}$

Em seu mais recente trabalho, Filosofia da educação: a relação educadoreducando e outras questões na perspectiva da educação ambiental ecomunitarista, Sirio Lopez Velasco apresenta o resultado de pesquisas e reflexões acerca de um tema central de seu pensamento: o ecomunitarismo, articulando-o em particular com a educação, mas não somente isso. Velasco propõe com o ecomunitarismo uma utopia pós-capitalista que contempla a economia ecológica, uma erótica da libertação, uma política de todos e uma comunicação livre e direta. Assim, os quatro capítulos que compõe o seu livro estão orientados por essa utopia.

A "Introdução" é direta e pontual e diz que a obra está no campo da Filosofia e mais especificamente no âmbito da Filosofia da Educação. A abordagem, por sua vez, combina a perspectiva histórica com a reflexão sistêmica.

Esta perspectiva histórica da abordagem compreende especialmente a primeira parte do capítulo um - "A relação educador-educando numa visão filosófica ecomunitarista” - cujo mote central é a reflexão filosófica sobre a educação, em particular sobre a relação educador-educando.

Incialmente o autor se concentra na filosofia hindu, na qual a relação do discípulo com o mestre passa pela obediência, respeito e disposição a ouvir, o mestre por sua vez ensina com gestos, palavras e exemplos. No centro desta relação está a verdade e seu ensino: o mestre é o porta-voz da sabedoria e da verdade e o

\footnotetext{
${ }^{1}$ Doutorando no Curso de Pós-Graduação (Stricto sensu) em Filosofia pela Universidade Estadual do Oeste do Paraná - UNIOESTE. E-mail: fabiobatista1985@bol.com.br.
} 
discípulo aquele que deseja a verdade. Velasco também enfatiza que a filosofia hindu implica a prática de uma forma de vida, isto é, que há uma identidade entre a filosofia e a vida.

Todavia, diz nosso autor, o ocidente pôs em questão a verdade representada pelo mestre e potencialmente adquirida pelo discípulo: o que é esta verdade? Podemos conhecê-la de forma plena? Ainda: "o educador é possuidor da verdade"? "Cabe transmiti-la ao discípulo, esperando dele obediência cega, reverência e serviço"? (VELASCO, 2018, p. 14). Isso porque o mestre hindu é um sábio, diz Velasco, Sócrates, na Grécia clássica, é um filósofo, alguém que tem amizade ou amor pelo saber e a sabedoria, e se dedica a buscá-los. A verdade, no caso da filosofia socrática, confundir-se-á com a definição correta buscada por meio do diálogo entre Sócrates e os seus interlocutores. "Agora, assim como se exigia na Îndia, também os mais insignes nomes da filosofia grega clássica defenderam a ideia de que o ensino do mestre deveria ter um eco perfeito na sua conduta para demonstrar sua solidez" (VELASCO, 2018, p. 17).

Da antiguidade passamos a Rousseau no século das Luzes: como o filósofo genebrino compreende a relação mestre-discípulo em sua filosofia da educação? Primeiro há que se dizer que Rousseau não passa na prova da concordância entre pensamento e vida, pois observa Velasco que o filósofo e autor do Émile entregou seus filhos a orfanatos, isto é, Rousseau apenas se dedicou ao aspecto teórico sem levar em consideração a prática. Embora, certamente e independente disso, seu pensamento sobre a educação seja de importância ímpar à filosofia da educação.

No seu Émile (1762) ao tratar da relação mestre-discípulo mostra "o que pode a educação de um homem" (VELASCO, 2018, p. 25). Émile passa assim por cinco etapas formativas demarcadas pela idade, do berço até o casamento, passando pela educação corporal, a aprendizagem de um ofício e posterior conhecimento especializado como a astronomia e as ciências naturais. Entre os quinze e vinte anos, passado já então por três fases, ele é introduzido na sociedade.

O filósofo uruguaio, Vaz Ferreira, também está entre os pensadores que dedicaram atenção ao problema da educação, considerando aspectos da educação doméstica e social, e a relação entre ciência e pedagogia, ou entre a tríade, ciência, pedagogia e filosofia, cabendo à ciência as questões e esclarecimentos sobre "o que o ser humano é, enquanto que a Filosofia (e a Pedagogia) lhes cabe o que se quer que o ser humano seja", diz nosso autor (VELASCO, 2018, p. 33) citando Vaz Ferreira.

Sobre a relação entre educador e educando, diz Vaz Ferreira, que ela compreende a dimensão teórica, mas também afirma que o ensino da moral é teórico e prático. E ainda que o educando deve ter uma mente aberta, uma atitude crítica e consciente daquilo que ignora. No entanto, não dispensa, no nível médio de ensino, que o professor assuma uma postura diretiva. 
Assim segue Velasco e aborda a educação, a relação educador-educando em Makarenko, educador soviético, cuja tônica é a disciplina, a consciência moral da responsabilidade e a compreensão da superioridade da vida coletiva sobre a individual.

Paulo freire, diz Velasco (2018, p. 50), "romperá com a tímida participação do discípulo no diálogo com o educador (observada em Sócrates e em Rousseau, e que sequer existe no ensino hindu), para propor a construção dialogal, entre educador e educando, do conhecimento".

Ainda no capítulo um, mas agora a partir de outro foco, nosso autor passa a considerar "a visão ecomunitarista da relação educador-educando", ou seja, encontramos aqui um desdobramento no que se refere ao campo temático e outro no da abordagem, respectivamente, trata-se da entrada em cena de modo explícito da perspectiva ecomunitarista e da reflexão sistêmica sobre essa relação a partir dessa perspectiva, destacando sempre a importância de três normas éticas: “1) que devemos lutar pela nossa liberdade individual de decisão, 2) que devemos vivenciar consensualmente essa liberdade, e, 3) que devemos preservar-regenerar de forma saudável a natureza humana e não humana" (VELASCO, 2018, p. 53-54). Em outras palavras, a partir desse ponto o autor passa a defender, em particular, suas teses sobre a filosofia da educação e, em geral, a sua filosofia ecomunitarista. Vale notar que o primeiro capítulo ocupa ao menos a metade do livro e está divido em torno de dois eixos, um descritivo-histórico e outro propositivo, como já aludimos.

No capítulo dois, "Notas sobre ecomunitarismo e esporte educativo e cooperativo", Velasco mostra seu conceito de esporte educativo e cooperativo a partir de sua perspectiva ética e ambiental, ecomunitarista. Sobre este ele diz: "Chamo de ecomunitarismo a ordem socioambiental pós-capitalista na qual os seres humanos reconciliam-se entre si para permitir e incentivar solidariamente o desenvolvimento pleno de cada sujeito, e se reconciliam com o restante da natureza, mantendo face a ela uma atitude permanente de preservação e regeneração" (VELASCO, 2018, p. 68). Com base nisso o autor propõe uma educação que dê a devida atenção ao corpo - pois, não devemos esquecer, diz ele, da importância que Platão dava a educação por meio da ginástica e da música antes mesmo da alfabetização.

O que está em questão aqui é, fundamentalmente, a concepção que temos da educação do corpo e sua relação com o esporte que na sociedade burguesa torna-se extremamente centrado na competitividade para fins lucrativos. Velasco propõe então outra concepção de esporte, uma reviravolta, pautada doravante na cooperação, respeito à liberdade individual, preservação da saúde e o respeito à natureza. 
Já o terceiro capítulo, "Explicitação dos conceitos das Diretrizes curriculares gerais nacionais para a educação ambiental", tem como objeto as diretrizes e conceitos centrais das Diretrizes Curriculares Nacionais para a Educação Ambiental (2012). Quais são elas? O que elas dizem? O autor nos mostra uma por uma e, de modo detalhado e rico, as comenta. Nós, a título de exemplo, apontaremos apenas algumas delas. Vejamos. 1. Visão complexa da questão ambiental, de modo a compreender que esta não está desvinculada de problemas econômicos, culturais e sociais. 2. Abordagem da educação ambiental de modo inter, multi e transdisciplinar contribuindo para a compreensão do valor da natureza para a vida, isto é, como fonte de vida e pluralidade étnico-racial. [...]. 10. Uma educação ambiental que mostre ao educando a importância de uma perspectiva sustentável, na qual ele se vê como agente da construção de uma sociedade menos degradante do humano e não humano, isto é, a natureza. As outras diretrizes ainda tratam de educação ambiental que proporcione a investigação com livre trânsito entre o saber formal (escolar-acadêmico) e as experiências dos povos originários e tradicionais sobre o meio ambiente.

Após passar anteriormente pela análise das diretrizes para a educação ambiental, Velasco propõe, no capítulo quatro - "Ideias para a educação ambiental ecomunitarista comunitária” - que encerra seu livro, ideias ecomunitaristas para a educação não-formal comunitária, "entendendo por tal toda prática com dimensão educativa consciente" (VELASCO, 2018, p. 101), podendo ocorrer através de vários agentes sociais: ONG's, movimentos populares, organizações políticas... Mostra aqui que a concepção de educação ecomunitarista, entre outros elementos, propõe o pleno desenvolvimento dos seres humanos, o que só poderá se realizar com a crítica permanente do capitalismo, dos seus horrores e formas de alienação. Pois, "Temos definido, diz Velasco (2018, p. 105) "o ecomunitarismo como sendo a ordem socioambiental sustentável pós-capitalista na qual realiza-se a reconciliação solidária entre os seres humanos, desde a escala local até a escala planetária, e a reconciliação entre os seres humanos e o restante da natureza, respeitando-se no dia a dia as três normas fundamentais da ética; assim, repetimos, o ecomunitarismo tem horizonte pós-capitalista pois o capitalismo violenta cotidianamente essas três normas fundamentais da ética" (VELASCO, 2018, p. 105).

A teoria educativa para educação ambiental comunitária de tipo ecomunitarista, diz o autor, é a chamada "pedagogia problematizadora", isto é, a conscientização ou o desvelamento crítico dialogado das relações de opressão e devastação próprias da nossa sociedade, a capitalista. Na qual a lógica do lucro, a guerra de todos contra todos e o aniquilamento ambiental imperam sobre a lógica da sustentabilidade e da liberdade, alcançadas apenas, enfatiza Velasco, em uma realidade pós-capitalista ecomunitarista. 
Por fim, vale reforçar, que o livro de Velasco, muito oportunamente em tempos de crise do pensamento utópico, trata, portanto, de questões permeadas pelo sabor do utópico e de um horizonte de liberdade a ser conquistado.

Submissão: 22.05.2019 / Aceite: 31.05.2019. 